\title{
Time-tested reliability of asphalt concretes on slag aggregates
}

\author{
Shtephan Yuriy Vitalievich \\ Moscow Automobile and Road Construction State \\ Technical University \\ Moscow, Russia \\ shtephan_y_v@mail.ru
}

\author{
Bondarev Boris Aleksandrovich \\ Lipetsk State Technical University, \\ "LipetskNICstrojproject" Ltd \\ Lipetsk, Russia \\ lnsp-48@mail.ru
}

\begin{abstract}
Researching results and monitoring urban highways with an upper layer of stone mastic asphalts on blastfurnace slag aggregates with a cuboid-shaped grain are presented in the paper. Crushed stone with such shape of grains is obtained after 3 stages of crushing on a modern domestic and imported crushing and sorting equipment. Relatively high properties of asphalt concretes on the basis of such aggregates have been confirmed by the tests' results. The optimality criterion and the MathCad software module have been used for the selection of well-graded aggregates. The exploitation of city road surfaces in Lipetsk, used without any intermediate repairs and defects for 13-14 years, has been a practical confirmation of such properties
\end{abstract}

Keywords-stone mastic asphalt, cast slag crushed stone, evenness of road surfaces, surface roughness.

\section{INTRODUCTION}

Nowadays due to a sharp increase in the speed of road traffic, the quality of road surfaces has significantly decreased. We have previously shown that the use of slag aggregates in asphalt concretes with surface porosity allows one to improve significantly the quality of road surfaces [1...3]. As noted in the paper [1], asphalt concretes on slag aggregates were used during capital repairs of city roads in Lipetsk in 2004-2005 on Pervomayskaya, Nedelina streets. At the same time, stone mastic asphalts (SMA) based on slag aggregates with a cubiform grain were used as wearing coats [2]. Crushed stone with such shape of grains was produced on special Hydrocone crushers of the Swedish firm Sandvik.

The results of laboratory and field studies of molten slag crushed stone obtained by a slow cooling of blast-furnace slags having a basicity factor $\geq 1$ are presented in the paper [3]. It is shown that having practically completed crystallization and surface porosity which increases the adhesion of aggregates to bituminous binders, such slags guarantee the maximum strength and abrasion resistance of asphalt coat

A high abrasion resistance of such wearing coats is also ensured by the use of bituminous binders activated with polymeric additives in asphalt concretes.

\section{RESEARCH RESULTS}

Additional tests of asphalt concretes based on slag aggregates and activated (modified) bituminous binders have been carried out in the present paper.
Such indices as the strength, the modulus of elasticity and viscosity of the undisturbed structure and the international roughness index (IRI) for SMA have been verified based in the completed research. These results have been processed in the Math Cad software module. The regression model formula described in the paper [2] has been obtained.

Compressive strength in coded values and the corresponding extreme values predicted by the model:

$$
\begin{aligned}
& p\left(x_{1}, x_{2}, x_{3}\right)=3.113+0.031 x_{2}-0.067 x_{3}-0.074 x_{1} \cdot x_{2} \\
& -0.178 x_{2} \cdot x_{3}+0.249 x_{1}^{2}-0.249 x_{2}^{2}-0.295 x_{3}^{2} \\
& p^{\max }(-1.215,0.318,-0.209)=3.504\{\mathrm{MPa}\} \\
& \text { Strength of } 15 \text { days saturated samples: } \\
& p n\left(x_{1}, x_{2}, x_{3}\right)=4.128+0.159 x_{1}+0.386 x_{2}+0.095 x_{3}+ \\
& +0.171 x_{2} \cdot x_{3}+0.07 \cdot x_{1} \cdot x_{3}+0.068 \cdot x_{1}^{2}- \\
& -0.523 x_{2}^{2}-0.181 \cdot x_{3}^{2} \\
& \operatorname{pn}^{\max }(1.215,0.489,0.736)=4.583\{\mathrm{MPa}\}
\end{aligned}
$$

We have developed a program for calculating the optimality criterion in the MathCad software module to further select optimal compositions that do not increase the cost of raw materials, payment options taking into account regression models and introduce new admissible limits that depend on the design requirements for asphalt layers in the construction of road pavements. The program is given the regression dependencies and constraints at the input of the algorithm based on the properties of asphalt concretes which are acceptable for this category of road. There is a possibility to specify the number of iterations indicating the start, the end and the step of the input parameter change respectively due to the cyclic implementation of the algorithm.

$K R=k r(h, b, a)-$ the dependence of the optimality criterion for the strength responses of dry and saturated samples calculated by formula:

$$
k r(h, b, a)=\frac{w}{0.554}+\frac{w d}{0.849}+\frac{3.504}{p}+\frac{4.583}{p n},
$$

where $w, w d$ - regression equations for responses, water short-term and long-term saturation, $p$, $p n$ - strengths at $20^{\circ} \mathrm{C}$ 
of dry and water-retained samples; numerical values are predicted by the extremes of the response surfaces.

It is necessary to set the limits of the interval for the change in the optimality criterion from $B$ to $E$ at the output of the calculation program.

The model maximum often falls to the boundary values of the examined space limited by changing parameters, which can be seen from the obtained regression equations. This indicates the need to introduce a special efficiency criterion in the planning model of the experiment and regression models which has allowed finding optimal compositions with high mathematical accuracy. The tests results are summarized in Table 1.

Comparing these tests results of asphalt concretes on slag aggregates with data [2] (see Table 3.7), it should be noted that they do not contradict the earlier studies and the researchers' conclusions [4]. The compressive strength of SMA at both $20^{\circ} \mathrm{C}$ and $50^{\circ} \mathrm{C}$ is within the limits of the standard parameters for this type of asphalt concretes. A similar conclusion can be drawn about other characteristics such as in place air voids, water saturation. It should be noted that the water saturation of asphalt concretes on slag aggregates having increased porosity is within the limits regulated by the standards for asphalt concretes on dense aggregates. This is explained by the fact that slag aggregates have an increased surface porosity. When the aggregates and bituminous binders are heated, they block these surface pores and do not allow water to pass into the inner layers of asphalt concretes.

TABLE I. CHARACTERISTICS OF SMA ON BLAST-FURNACE SLAG AGGREGATES WHICH MIXTURES HAVE BEEN DEVELOPED BY US EARLIER

\begin{tabular}{|l|l|l|l|l|}
\hline $\begin{array}{c}\text { Experim } \\
\text { ent No. }\end{array}$ & $\begin{array}{c}\text { Compressive } \\
\text { strength at } \\
\mathbf{2 0 0 C},\{\mathbf{M P a}\}\end{array}$ & $\begin{array}{c}\text { Compressive } \\
\text { strength at } \\
\mathbf{5 0 0 C},\{\mathbf{M P a}\}\end{array}$ & $\begin{array}{c}\text { In place } \\
\text { air voids, } \\
\text { \{\% by } \\
\text { volume }\}\end{array}$ & $\begin{array}{c}\text { Water } \\
\text { saturation, } \\
\{\% \text { by } \\
\text { volume }\}\end{array}$ \\
\hline 1 & 3.59 & 0.62 & 2.93 & 3.52 \\
\hline 2 & 3.14 & 0.57 & 3.68 & 3.32 \\
\hline 3 & 3.66 & 0.63 & 3.58 & 2.87 \\
\hline 4 & 4.03 & 0.66 & 3.60 & 3.32 \\
\hline 5 & 3.88 & 0.57 & 2.87 & 3.15 \\
\hline 6 & 3.72 & 0.62 & 3.48 & 2.78 \\
\hline Av. & 3.67 & 0.61 & 3.36 & 3.16 \\
\hline
\end{tabular}

The Lipetsk road network in $550 \mathrm{~km}$ financed under "The Lipetsk Program for the Economic and Social Development until 2016" has been periodically monitored after major repairs and renovations since 2003. Among the examined factors of a transportational and operational condition: the smoothness of urban road surfaces, the adhesion ability of the asphalt coat, mechanical strength characteristics and smoothness indices according to the IRI. Clear priorities are used for the operational planning of roadwork in Lipetsk road facilities in order to maximize the return from the allocated funds [10]. The influence assessment of the road surface quality based on SMA with the cast slag crushed stone on the grip of the asphalt coat with the car wheel while moving has been also made.

The condition of the road surface on the adhesion ability has been assessed by comparing the actual value of the longitudinal coupling coefficient with its admissible limit value. The road surface meets the operating requirements if the actual adhesion coefficient is greater than or equal to the admissible limit value. The admissible limit value of the longitudinal coupling coefficient is established in the Russian National Standard GOST R 50597-93 "Automobile roads and streets. The requirements to the level of maintenance. Satisfied the traffic safety". According to the conditions for ensuring road safety it is 0.3 when measured by a tire without a tread pattern and 0.4 when measured by a tire having a tread pattern [6].

The reliability index of the car tire contact with a road surface is the resistance value to an automobile tire sliding on the roadway surface which is estimated by the value of the adhesion coefficient. This coefficient is calculated from the ratio of the reactive force acting on the car wheel in plane of its contact with the coating to the magnitude of the vertical load transmitted by the wheel to the coating. The adhesion coefficient by its physical essence is the friction coefficient of a rubber tread of car tire with the road surface. The frictional force depends on the quality of the paving material, the duration contact as well as the presence of water, motor oil or fuel, dust, defects on the road surfaces etc. Therefore, the new national standard [7] provides measuring the adhesion coefficient not by a portable control device PPC-MADI, but by the roughmeter method while measuring by a device to control the evenness and slipperiness of road surfaces PCRS-2 at the recommended measurement speed of $50 \mathrm{~km} / \mathrm{h}$ or by the method [8] which is difficult to implement in the megapolises traffic congestion. Neither method is able to take into account all these factors when measuring on the surface, only modern mobile road scanners can cope with it, for example a car road scanner ADS-MADI ${ }^{\circledR}$ or $3 \mathrm{D}$ scanners are tested for texture evaluation, mainly the ZScanner ${ }^{\circledR} 800$ (Slovakia) [11]. There studies showed that more than two accelerometers are required [12] for detecting defects which is achieved on these scanners. The estimation of coupling properties of the road surface can be made by comparing actual values of the adhesion coefficient with the established admissible limit values.

The lane adhesion coefficient values with the worst coupling properties can be used to estimate the adhesion of the coating on a road segment. The determination of the adhesion coefficient should be carried out on special equipment in accordance with the requirements of Industry Road Standards INR 218.0.006-2002. The adhesion coefficient value is affected by a set of factors related to road surfaces. In particular, it is affected by the following characteristics of road surfaces:

- the coating roughness (the larger it is, the greater the area of its contact with the tire and the higher the adhesion level which causes an increase in the adhesion coefficient); the maximum height of the coating projections should be $<5 \mathrm{~mm}$. Higher roughness helps to reduce the adhesion coefficient. The tire maintains contact with the roadway with an allowable 
roughness of the coating and does not form a continuous water layer because of the rain which reduces the cohesion of coated tires. The adhesion coefficient is significantly influenced by the micro-roughness of aggregates of asphalt concretes and the road surfaces roughness too;

- the surfacing type and its useful life (the adhesion coefficient is reduced by decreasing the roughness with increasing useful life after constructing or repairing the pavement; the adhesion coefficient reaches its greatest value for cement-concrete coatings in a dry state with useful life up to $10 \ldots 12$ years and for asphalt-concrete ones - 5 ... 8 years; the adhesion coefficient decreases by $30 \ldots 40 \%$ after the coating wear-out by $50 \ldots 60 \%$; the adhesion coefficient is significantly reduced as the tires are polished with asphalt concretes);

- the roadway roughness (the adhesion coefficient is reduced due to changing conditions at the point of the tires contact with the coating surface and because of the separation of wheels from the road surface on the potholes).

In addition, the adhesion coefficient value is significantly affected by the condition of the pavement (the coating smoothness) and the characteristics of vehicles wheels.

In Fig. 1 it can be seen that the greatest indicators of coupling properties have the road surfaces in Nedelina Street where the upper layer has been made of SMA on blast-furnace slag aggregates with a cuboid-shaped grain.

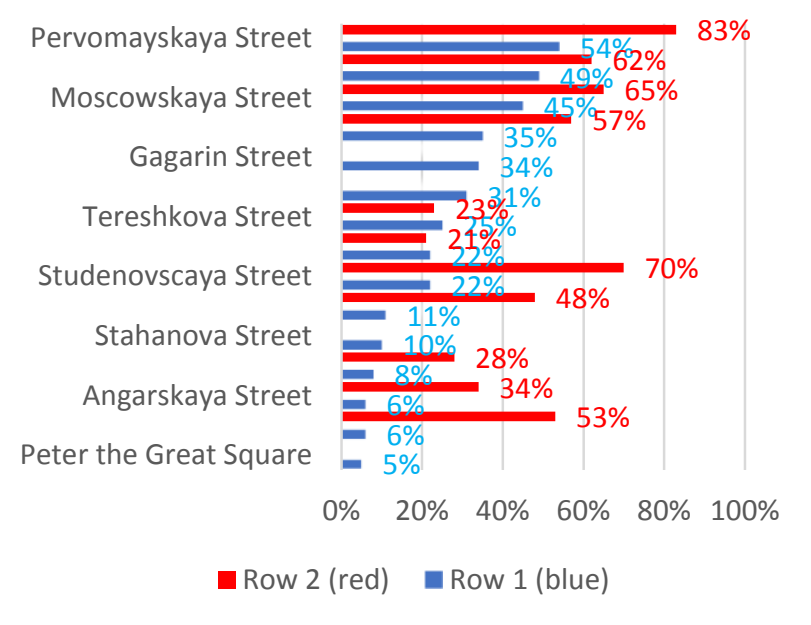

Fig. 1. The monitoring results of city road surfaces in Lipetsk. The coating proportion having regulatory properties. (Row 1 (blue) - areas with normative coupling properties of the coating, Row 2 (red) - areas with a standard evenness)

This is due to the presence of micro-roughness in such a crushed stone which increases the adhesion of automobile tires to the road surface. According to the monitoring results the complex index of these objects after 6 years of using has been maximal too [10].

Data analysis of roadway pavings in Lipetsk has showed that disregarding construction technologies, drainage errors, increased traffic intensity and untimely road repair and maintenance cause the deterioration of their coupling properties and accelerated wear.

This work results used in major road repairs in Pervomayskaya and Nedelina Streets in Lipetsk in 2004 have shown and continue to maintain high quality indicators for road surfaces without such repairing up to now (see Fig. 2, 3).

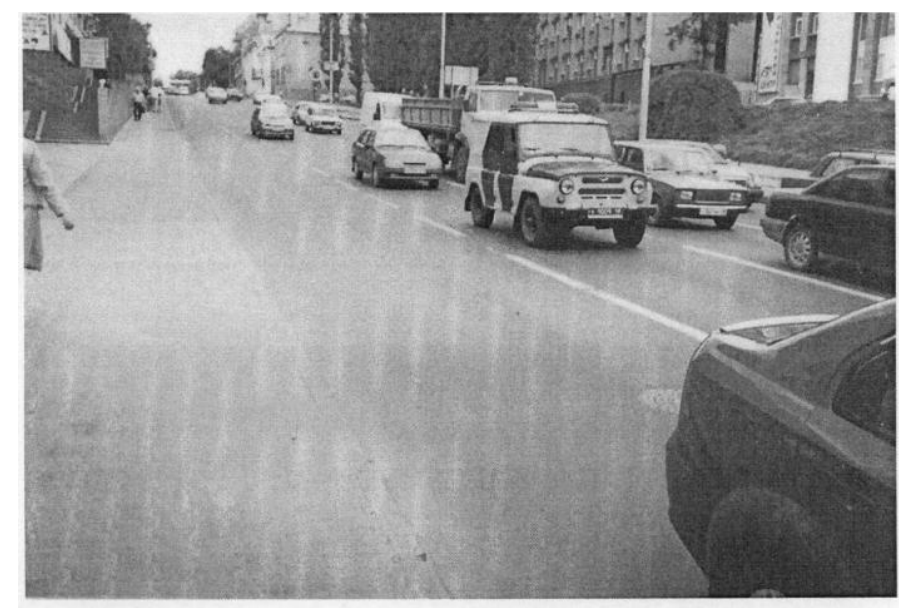

Fig. 2. The condition of road in Pervomayskaya Street in Lipetsk

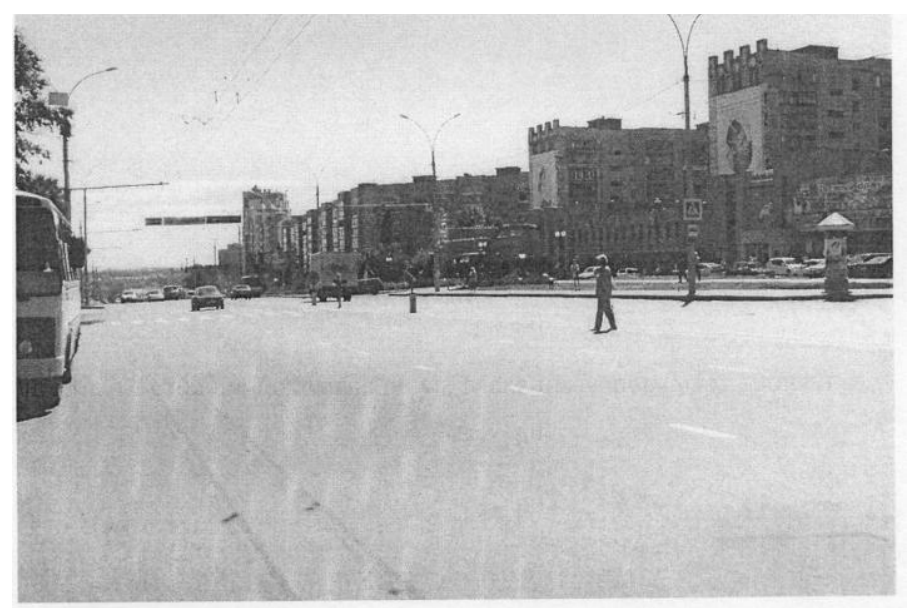

Fig. 3. The condition of road in Nedelina Street in Lipetsk

In Fig. 3 it can be seen that despite the considerable slope, the condition of asphalt-concrete road based on slag aggregates is sufficiently smooth and has no defects.

At the same time, using modern technologies with SMA and macro-rough aggregates in the composition of cast slag crushed stone allows one to increase the useful life of road surfaces, ensuring high coupling properties of road surfaces and increasing their abrasion resistance.

Thus research results presented in this paper have proved high physical and mechanical properties of SMA on blastfurnace slag aggregates which have almost complete crystallization and provide increased strength and abrasion resistance to asphalt concretes due to high adhesion to binders.

\section{SUMMARY}

1. Research results carried out in the present paper have showed the high physical and mechanical properties of SMA 
on blast-furnace slag aggregates having almost complete crystallization and providing increased strength and abrasion resistance to asphalt concrete pavements.

2. The model maximum often falls to the boundary values of the examined space limited by changing parameters which can be seen from the obtained regression equations. This indicates the need to introduce a special efficiency criterion in the planning model of the experiment and regression models which has allowed finding optimal compositions with high mathematical accuracy.

3. The 14-year use of experimental sections of Lipetsk roads without intermediate repairs and monitoring results are a practical evidence of high strength and abrasion resistance of SMA on blast-furnace slag aggregates.

\section{References}

[1] B.A. Bondarev, Yu.V. Stefan and others, Asphaltic concretes on slag aggregates. Lipetsk: LSTU, Russia, 2005.

[2] Yu.V. Shtephan, B.A. Bondarev, L.A. Prozorova, Integrated quality management of stone mastic asphalts on blast-furnace slag aggregates. Tambov: ed. Pershin R.V., Russia, 2016

[3] B.A. Bondarev, Yu.V. Shtephan, "Studies of SMA on blast-furnace slag aggregates in laboratory and field conditions", Engineering systems and facilities, vol. 4 (17), pp. 13-20, 2014
[4] D.A. Strizhevsky, L.V. Yankovsky, A.V. Kochetkov, "Study of improving road safety by taking into account the IRI index and the complex indicator of the transport and operational status", Technical regulations in transport construction, vol. 3, pp. 7-11, 2014.

[5] Yu.V. Shtephan, Yu.E. Vasiliev, V.V.Talalay, "Technical regulation and quality control of road construction materials and performed repairs in urban conditions", Russian Road Worker, vol. 24, dated June 8 http://www.aspor.ru/publishers/?page=pages_1535, 2017.

[6] A.V. Kochetkov, L.V. Yankovsky, Yu.A. Trofimenko, "Developing technologies of the application of thin wear layers and rough road surface treatments", Science, vol.4 (23), July - August 2014. Internet publication: https://naukovedenie.ru/PDF/79TVN414.pdf pp.1-20.

[7] GOST R 56925-2016 Automobile roads and airfields. Unevenness measurement methods for base courses and pavements.

[8] S.P. Arzhanukhina, Zh.N. Kadyrov, A.V. Kochetkov, I.G. Shashkov, V.V. Ermolayeva, "Method for determining the coefficient of adhesion of the automobile wheel with the road", Naukovedenie, vol. 7, \#3, http://naukovedenie.ru/PDF/76TVN315.pdf, pp. 1-10, 2015.

[9] V.V. Stolyarov, Engineering of highways taking into account the risk theory. Sarat. state. tech. un. - Saratov: SSTU, Russia, 1994. Part 1.

[10] A.V. Ponomarev, "Development of methods for improving the transportoperational condition of urban highways", Candidate thesis in Engineering Science 05.23.11, Russia, Volgograd, 2009.

[11] J. Čelko, M. Kováč, P. Kotek, "Analysis of the Pavement Surface Texture by 3D Scanner", Transportation Research Procedia, vol.3, pp. 2994-3003, 2016.

[12] S.C. Radopouloua, I. Brilakis, "Improving Road Asset Condition Monitoring", Transportation Research Procedia, vol. 14, pp. 3004-3012, 2016. 